\title{
CONJETURAS NIETZSCHEANAS SOBRE EL COMIENZO DE LA CIVILIZACIÓN. UN ENSAYO DE PSICOPATOLOGÍA DE LA CULTURA
}

\author{
JULIO BELTRÁN
}

INSTITUTO DE INVESTIGACIONES FILOSÓFICAS

UNIVERSIDAd NACIONAL AUTÓNOMA DE MÉXICO

El segundo tratado [de mi Genealogía de la moral] ofrece la psicología de la conciencia: ésta no es, como se cree de ordinario, "la voz de Dios en el hombre", - es el instinto de la crueldad, que revierte hacia atrás cuando ya no puede seguir desahogándose hacia afuera. La crueldad [es] descubierta aquí por vez primera como uno de los más antiguos trasfondos de la cultura, con el que no se puede dejar de contar.

Ecce Homo, "Genealogía de la moral. Un escrito polémico"

\section{Introducción}

“'Culpa', 'mala conciencia' y similares”, el segundo ensayo de la Genealogía de la moral de Nietzsche (GM), contiene muchas de las tesis principales de su concepción de la historia humana, cómo empezó y qué curso tenía que tomar según él. Trata específicamente de lo que me atrevo a llamar una psicopatología de la civilización. Su hipótesis principal surge en el decimosexto párrafo (16), y cuyo pasaje central dice:

Yo considero que la mala conciencia es la dolencia a que tenía que sucumbir el hombre bajo la presión de aquella modificación, la más radical de todas las experimentadas por él, -de aquella modificación ocurrida cuando el hombre se encontró definitivamente encerrado en el sortilegio de la sociedad y de la paz. [...] Pero con ella se había introducido la dolencia más grande, la más siniestra, una dolencia de la que la humanidad no se ha curado hasta hoy, el sufrimiento del hombre por el hombre, por si mismo: resultado de una separación violenta de su pasado de animal, resultado de un salto y una caída, por así decirlo, en nuevas situaciones y en nuevas condiciones de existencia, resultado de una declaración de guerra contra los antiguos instintos en los que hasta ese momento reposaban su fuerza, su placer y su fecundidad. ${ }^{1}$

1 GM II 16. Dada la brevedad de los párrafos de Nietzsche, considero innecesario dar su paginación, basta con la numeración que el propio Nietzsche proporciona. En general, sigo 
Hay cinco tesis notables en este pasaje:

1) que el cambio más fundamental del hombre, aquel que marca el comienzo de la historia humana, se debió a la tensión sufrida cuando tuvo que renunciar a la guía de los instintos y confiar, en cambio, en su reflexión consciente;

2) que la renuncia a la guía de los instintos sobrevino con la entrada del hombre en sociedad o, más precisamente, cuando el hombre fue forzado a entrar en ella;

3) que fue la paz de su nuevo confinamiento, más que la violencia del proceso, lo que más tensión causó en el hombre, pues los antiguos instintos continuaban demandando satisfacción;

4) que el hombre terminó, así, por estar en contradicción consigo mismo, "inventando" la mala conciencia, "malos ojos" para ver sus propias inclinaciones naturales, $y$

5) que esto a su vez causó la más grave enfermedad psicológica de la humanidad, a saber, "el sufrimiento del hombre por el hombre, por sí mismo" (lo que más adelante Nietzsche llama también "la náusea más grande, la voluntad de nada, el nihilismo").

Para analizar, interpretar y explicar la articulación de estas tesis necesitaré exponerlas en el contexto del ensayo " 'Culpa', 'mala conciencia' y similares" y contrastarlas con otras concepciones. Para ello he seleccionado una versión muy simplificada de la concepción cristiana "tradicional": las conjeturas de Kant sobre el comienzo de la historia humana y el drama musical de Wagner sobre El anillo del nibelungo.

\section{La concepción cristiana tradicional y las conjeturas kantianas}

De acuerdo con la interpretación común cristiana, el hombre es culpable de malemplear la "libertad" que le fue concedida, pues sigue sus "impulsos animales" cuando debería obedecer las leyes morales que le han sido dictadas en la forma de "conciencia moral". De acuerdo con esto, la libertad es considerada la posibilidad de obedecer o bien la conciencia y hacer el bien, o bien los impulsos animales y hacer el mal. Pero como el hombre escoge el mal, todos los dolores que él y otros humanos "sufren" son causados y por lo tanto merecidos por él, en primer lugar; aunque también le son útiles, en segundo lugar, pues despiertan su conciencia. En efecto, este sufrimiento se justifica como la única manera que el hombre tiene de llegar a darse cuenta de sus faltas y "arrepentirse" de ellas, o sea, en que aprende la frase: "No

las traducciones de Andrés Sánchez Pascual, publicadas por la Alianza Editorial de Madrid, aunque con pequeños cambios ocasionales. 
debo...". En términos religiosos, aquel abuso de la libertad cuenta como un "pecado" no sólo del primer hombre sino, recurrentemente, de cada hombre. El supuesto reconocimiento de que él mismo es la causa libre de sus sufrimientos es lo que se llama "culpa o mala conciencia".

Esta visión cristiana se ha incorporado frecuentemente a la filosofía moral. Veamos por ejemplo las conjeturas de Kant acerca del mismo comienzo de la historia humana: ${ }^{2}$

Antes de despertar la razón [en el ser humano] [...] y, con todo lo débil que es, porfiar con la animalidad y su entera fuerza, tuvieron que originarse males. [...] El primer paso que traspuso este estado [de naturaleza] fue, en el aspecto moral, una caída [en el pecado]; en el aspecto físico, la consecuencia fue toda una serie de males no conocidos por la vida [...]. La historia de la Naturaleza empieza, por consiguiente, con bien, pues es la obra de Dios; la historia de la libertad con mal, pues es la obra del hombre. [...] [El hombre], por lo tanto, tiene motivos para atribuir a su propia culpa todos los males que soporta y todas las maldades que practica. ${ }^{3}$

Según Kant, la emancipación del hombre de la guía de la naturaleza comenzó cuando el hombre cobró conciencia de su "voluntad libre" y de su "razón", i.e., de su facultad para escoger libremente su propia manera de vida de acuerdo con razones. Esta facultad abrió la posibilidad para él de escoger entre el "mal" y el "bien"; aunque ni el primero se identifique automáticamente con sus impulsos animales, ni el segundo con su razón. El mal resultó, más bien, del conflicto entre ambas tendencias dentro del hombre. No obstante, el primer experimento del hombre en materia de opción libre resultó en mal, sufrimiento, "castigo" y, por lo tanto, desde el punto de vista del propio hombre, en algo de lo que debe culparse a sí mismo, en "pecado".

Ahora bien, Kant supone que el estado original del hombre era un estado de inconsciente obediencia a los instintos naturales. Pero también admite que el fin último de la historia debe ser el tipo de hombre autónomo o, más precisamente, la república perfecta, una constitución social compatible con la autonomía de todos sus miembros ("el problema más difícil para la razón"). De aquí que Kant divida la historia en dos movimientos, con un punto de inflexión: el primer movimiento va de un estado original de naturaleza, en el que el hombre obedece a sus instintos con una buena conciencia, a un estado moral. En este primer camino, el hombre tiene que forcejear constantemente contra las instancias de los antiguos impulsos naturales. Cuando el hombre haya alcanzado este punto intermedio, entonces podría empezar el segundo movimiento, es decir, un retorno a la naturaleza, cuyo

2 Kant, "Comienzo presunto de la historia humana" (1786), en Filosofía de la historia, trad. Eugenio Ímaz, FCE, México, 1985, pp. 67-95.

3 Kant, op. cit., pp. 78-79. 
fin último es un estado en el que la voluntad racional y los impulsos naturales mantengan un perfecto acuerdo.

La salida del hombre de [...] la primera estación de la especie no significa otra cosa que el tránsito de la rudeza de una pura criatura animal a la humanidad, el abandono del carromato del instinto por la guía de la razón, en una palabra: de la tutela de la Naturaleza al estado de libertad. ${ }^{4}$

Por consiguiente, aunque la emancipación de la tutoría de la naturaleza haya representado progreso para el hombre como especie, también tuvo que representarle una caída como individuo, pues la transición implica un continuo estado de conflicto entre sus facultades, del cual surgen el mal y el sufrimiento. Parafraseando a Rousseau, Kant considera este conflicto, entre el destino moral del hombre y su carácter de especie natural, como una:

[c]ontradicción de la cual [...] nacen todos los males que pesan sobre la vida humana y todos los vicios [...] [Sin embargo] las incitaciones al vicio a las que se hecha culpa son en sí mismas buenas y, como disposiciones naturales, adecuadas. [El único problema es que] como estas disposiciones estaban preparadas para el estado natural sufren violencia con el avance de la cultura, y ésta sufre con ellas, hasta que el arte perfecto se convierte en naturaleza [para que se resuelva el conflicto]; que es en lo que consiste la meta final del destino moral de la especie humana. ${ }^{5}$

En la explicación kantiana no queda claro, sin embargo, si la conciencia humana de la razón despertó con la constitución de la sociedad y debido a ella, como declara Nietzsche. De cualquier modo, hay otras similitudes entre estos dos autores que trataré de mostrar en lo sucesivo.

\section{Las condiciones psicológicas de la civilización}

Casi todo lo que nosotros denominamos "cultura superior" se basa en la espiritualización y profundización de la crueldad - tal es mi tesis.

Más allá del bien y del mal 229

La espiritualización y "divinización" siempre crecientes en la crueldad [...] atraviesan la historia entera de la culkura superior (y tomadas en un importante sentido incluso la constituyen).

GM II 6

Para Nietzsche, la emancipación del hombre de la guía de la naturaleza significa un proceso muy largo, la parte más amplia, según él, de la historia

4 Kant, op. cit., pp. 78-79.

5 Kant, op. cit., p. 80 
de las sociedades, la fase "prehistórica". En general, Nietzsche concibe la historia entera como el progreso del hombre hacia una última meta, implícita en su naturaleza: criar conciencia o, en las palabras de Nietzsche, llegar a ser "un animal con el derecho a hacer promesas". 6 La actualización de esta facultad resume el desarrollo de todas las capacidades humanas. Esta facultad representa una habilidad para ordenar el futuro de antemano y es por tanto el extremo opuesto al estado natural del hombre, en el cual sólo le ocupa el presente.

Ahora, alcanzar tal facultad es algo bastante paradójico, como Nietzsche admite, pues la antigua "esclavitud al instante" no es una condición meramente privativa e inerte del hombre, una simple carencia, sino una fuerza natural activa de olvidar e inhibir, un instrumento que regula la incorporación de experiencias en la conciencia y, por lo tanto, una fuerza adecuada para proteger su vida. Esta saludable facultad está claramente en conflicto con la facultad buscada de hacer promesas, pues esta segunda facultad requiere una fuerza opuesta de retención, "una memoria con cuya ayuda la capacidad de olvido queda en suspenso en algunos casos, a saber, en los casos en que hay que hacer promesas".?

Dadas estas condiciones, durante la parte más vieja y más larga de su historia, el hombre se consagró a resolver la contradicción entre la fuerza activa de olvidar y la fuerza buscada para retener ciertas experiencias. La manera en que esto se hizo, según él, fue engendrar un tipo intermedio de hombre, no totalmente olvidadizo pero aún incapaz de hacer sus promesas; un hombre forzado a recordar y forzado a hacer y a mantener promesas. Esto es lo que podemos llamar el tipo moral de hombre. Una humanidad moral era, pues, la condición de posibilidad de la vida en común y una existencia más o menos planificada.

Para disponer [...] anticipadamente del futuro - dice Nietzsche- I [...] debe haber aprendido antes el hombre a separar el acontecimiento necesario del casual, a pensar causalmente, a ver y anticipar lo lejano como presente, a saber establecer con seguridad lo que es fin y lo que es medio para el fin, a saber en general contar, calcular - cuánto debe el hombre mismo, para lograr esto, haberse vuelto antes calculable, regular, necesario, incluso en su propia presentación de sí mismo, si es que finalmente ha de poder responder de su propio futuro, que es lo que hace quien promete ${ }^{8}$

Ésta es cabalmente la larga historia de la procedencia de la responsabilidad. Aquella tarea de criar un animal al que le sea lícito hacer promesas incluye en sí como condición y preparación, según lo hemos comprendido ya, la tarea

8 GM II 1 (traducción mía). 
más concreta de hacer antes al hombre, hasta cierto grado, necesario, uniforme, igual entre iguales, ajustado a la regla, y, en consecuencia, calculable. ${ }^{9}$

Desde el punto de vista del hombre, toda esta labor estaba orientada al fin de constituir un Estado a partir de una muchedumbre salvaje; una labor de domesticación, llevada a cabo principalmente por medio de códigos penales y castigos, lo que Nietzsche llama "eticidad de las costumbres".

Aquella tarea de criar un animal al que le sea lícito hacer promesas incluye en sí como condición y preparación, según lo hemos comprendido ya, la tarea más concreta de hacer antes al hombre, hasta cierto grado, necesario, uniforme, igual entre iguales, ajustado a la regla, y, en consecuencia, calculable. El ingente trabajo de lo que yo he llamado "eticidad de la costumbre" -l auténtico trabajo del hombre sobre sí mismo en el más largo periodo del género humano, todo su trabajo prehistórico, tiene aqui su sentido, su gran justificación, aunque en él residan también tanta dureza, tiranía, estupidez e idiotismo: con ayuda de la eticidad de la costumbre y de la camisa de fuerza social el hombre fue hecho realmente calculable. ${ }^{10}$

Al final, los Estados u hombres gobernantes alcanzaron su meta. Pero simultáneamente produjeron "culpa o mala conciencia", la fuente de la enfermedad más grave entre sus súbditos, en opinión de Nietzsche.

Así, habría diferentes clases de conciencia unidas a los diferentes estados de la humanidad. El hombre, dice Nietzsche, tiene una buena conciencia o se siente a sí mismo inocente, tanto en su estado original de naturaleza y en un prometido estado final de soberanía o autonomía. Pero en su largo estado intermedio, en el "estado de moralidad" ("puesto que 'autónomo' y 'moral', dice, se excluyen mutuamente"), el hombre tuvo que crearse una conciencia culpable. Y puesto que la primera inocencia debe concebirse como algo más bien inconsciente, sólo la segunda inocencia es propiamente la buena conciencia: el estado acabado del hombre. Tenemos, pues, tres diferentes estados de moral en el hombre: no conciencia, mala conciencia y buena conciencia. Me parece que la tesis de Nietzsche es la siguiente: que la mala conciencia era una fase de la psique humana, tan necesaria como el mismo hombre moral para que éste llegara a cobrar conciencia, si alguna vez había de hacerlo. 


\subsection{La acción del "Estado"}

[E]l "Estado" más antiguo apareció, en consecuencia, como una horrible tiranía, como una maquinaria trituradora y desconsiderada, y continuó trabajando de ese modo hasta que aquella materia bruta hecha de pueblo y de semianimal no sólo acabó por quedar bien amasada y maleable, sino por tener también una forma.

GM II 17

Para entender la interpretación nietzscheana de la historia es importante tener presente su rechazo de la teoría del contrato como origen de la sociedad. Su concepción se guía más bien por la tesis de que todas las sociedades fueron constituidas por la acción espontánea de los "Estados", donde "Estado" significa la fuerza formadora de un "señor" o artista político ("una horda cualquiera de rubios animales de presa, un conquistador y señor"), quien aparece de repente e imprime su voluntad en una población informe. ${ }^{11}$ Así, las sociedades más antiguas fueron producto de la habilidad política y la tiranía, y de ninguna manera el resultado de contratos. Este hecho explicará muchas de las consecuencias que Nietzsche deriva de las condiciones de la vida en sociedad, especialmente aquellas relacionadas con la formación de una mala conciencia.

La tesis sociológica de la acción espontánea del señor es una consecuencia de un principio biológicơ y más fundamental para Nietzsche, según el cual una voluntad de poder, un instinto de libertad, es la esencia de la vida. ${ }^{12}$ Suponiendo un instinto tan indomitable en los hombres, un contrato social espontáneo resulta más bien improbable. Antes bien, por sí mismo ese instinto tiene una fuerza dispersante y para que los hombres llegaran a ser un todo organizado, parece necesario el trabajo de un señor, una fuerza superior que las rebasara a todas e imprimiera, sobre esa población, una forma afín a su intereses particulares.

Así es como, en efecto, se inicia en la tierra el "Estado": yo pienso que así queda refutada aquella fantasía que le hacía comenzar con un "contrato". Quien puede mandar, quien por naturaleza es "señor", quien aparece despótico en obras y gestos - iqué tiene que ver él con contratos! ${ }^{13}$

Pasemos a ver la naturaleza de ese instinto de libertad o voluntad de poder que actúa en cada criatura viviente. ${ }^{14}$ Según la teoría, cada hombre es llevado por una fuerza que incorpora todos los objetos necesarios para

11 GM II 17.

12 GM II 12.

13 GM II 17.

14 El más antiguo antecedente de estas ideas se encuentra, como se ha hecho notar repetidas veces, en el concepto de "conatus" de Spinoza. 
mantenerlo vivo o que aumenten su poder. Esto no es más que la fuerza elemental en cada organismo para mantener la vida y acrecentar su complejidad orgánica. Esta fuerza se expresa en varias inclinaciones naturales. Y como no hay ninguna otra fuerza que gobierne a las criaturas vivientes, no hay preocupaciones que impidan al hombre hacer lo que más convenga a sus necesidades presentes, cualesquiera que éstas sean. Por ejemplo, la voluntad de poder se puede expresar en el modo de esa fuerza para olvidar a la que ya me he referido, o en el modo de autonomía, un modo de mucho mayor complejidad orgánica de la vida, pues en él el hombre dispone del futuro por adelantado. La vida se esfuerza siempre por alcanzar más altos niveles de organización y, en el caso del hombre, por alcanzar el nivel de autonomía. El hecho de que la tarea de crear una memoria en el hombre parezca paradójico, se debe a que, en ella, la voluntad de poder tiene que trabajar contra sí misma. La paradoja radica en la contradicción de concebir que un mismo principio pueda limitarse a sí mismo sin suponer otro principio opuesto. La solución de Nietzsche, como la veo, consiste en la acción de múltiples individuos guiados por el mismo principio, el mismo conato en cada individuo de modo que se limiten unos a otros. Sólo esta solución pluralista haría más claro el hecho de que algunos animales hayan inhibido su facultad para olvidar.

3.1.1. La voluntad de poder activa en el artista político. La acción de estos señores es una expresión de la voluntad de poder: un tránsito hacia organizaciones más y más complejas, en las cuales el señor incorpora violentamente otros seres como partes de una forma de ellos mismos y les asigna nuevas funciones subordinadas. El señor organiza su entorno de acuerdo con su propia voluntad y la forma concebida. Esta organización del entorno asegura, pero sobre todo acrecienta, su vida. No debe confundirse a estos señores con la forma acabada de hombre de la que hablamos antes, con el hombre de conciencia, con el hombre que tiene el derecho de hacer promesas, etc. Puesto que mientras esta fase última del hombre presupone el camino largo a través del hombre calculable y uniforme de la mala conciencia, esos que son "señores por naturaleza" están bastante más cercanos al estado natural, aunque, afortunadamente y a diferencia de otros hombres, dotados de una tremenda fuerza y voluntad de poder. Son genios, tipos afortunados en cuyos oídos habla la naturaleza misma:

Su obra es un instintivo crear-formas, imprimir-formas; son los artistas más involuntarios, más inconscientes que existen: -en poco tiempo surge, allí donde ellos aparecen, algo nuevo, una concreción de dominio dotada de vida, en la que partes y funciones han sido delimitadas y puestas en conexión, en la que no tiene sitio absolutamente nada a lo cual no se le haya dado antes un "sentido" en orden al todo. Estos organizadores natos no saben lo que es culpa, lo que 
es responsabilidad, lo que es consideración. [...] No es en ellos en donde ha nacido la "mala conciencia". ${ }^{15}$

3.1.2. La naturaleza dispersiva de la voluntad de poder que el señor necesita superar. De cualquier modo, la "población" sobre la que trabaja este organizador artista de la política no es materia muerta. Es amorfa, desde luego, precisamente porque en cada uno de sus miembros vive un pequeño instinto de libertad, una fuerza para olvidar, una menor cantidad de voluntad de poder y antes de la súbita aparición de un señor, ellos hacían efectiva esta libertad. El señor o el proto Estado tuvo que superar una tendencia natural de la muchedumbre a dispersarse, o en palabras de Nietzsche, tuvo que "expeler del mundo una tremenda cantidad de libertad". Este proceso no es otra cosa sino la tarea antes referida de hacer al hombre calculable y uniforme. Está claro ahora que el trabajo de ese artista político necesitó de la violencia, "martillazos" para superar el instinto de libertad por parte de los hombres de la muchedumbre que, de ser individuos libres, eran convertidos en partes subordinadas de un nuevo organismo.

[L]a inserción de una población no sujeta hasta entonces a formas ni a inhibiciones en una forma rigurosa iniciada con un acto de violencia fue llevada hasta su final exclusivamente con puros actos de violencia... ${ }^{16}$

3.1.3. La violencia de la acción formadora del señor. Para organizar una sociedad, el Estado más antiguo tuvo que hacer a sus sujetos calculables y así confeccionar una memoria en ellos con unas cuantas reglas para la vida común, un par de "no debo" que fueran impuestos. Esto a su vez significó superar la fuerza natural para olvidar. Los medios que utilizó el Estado contra dicha fuerza fueron dolor, castigo y sufrimiento. El fundamento de la más antigua mnemónica es que "sólo lo que no cesa de doler permanece en la memoria". ${ }^{17}$ Es por esto que el periodo en que la humanidad creó una memoria fue tan cruel.

Cuando el hombre consideró necesario hacerse una memoria, tal cosa no se realizó jamás sin sangre, martirios, sacrificios [...] todo esto tiene su origen en aquel instinto que supo adivinar en el dolor el más poderoso medio auxiliar de la mnemónica. ${ }^{18}$

Los códigos penales fueron especialmente inventados para fijar las demandas básicas de una existencia social en la mente de aquellos "esclavos de los afectos momentáneos". Y de acuerdo con la máxima de la mnemónica,

\footnotetext{
15 GM II 17.

16 GM II 17.

17 GM II 3.

18 GM II 3.
} 
estos códigos son más severos cuanto más fuerte es el olvidar que han de domeñar. Los castigos que imponen son para el sujeto castigado, pero son aún más para los espectadores. De esta manera es imposible olvidar las promesas empeñadas a fin de disfrutar de los privilegios de la sociedad. A la larga, esta memoria, formada y ahondada una y otra vez a la vista de crueles castigos, llegó a ser razón, dominio de los afectos, reflexión. Al final, el hombre fue domado y hecho calculable, uniforme y predecible.

3.1.4. Interrupción de la guía de los instintos. Es también notable que la constitución de las sociedades más antiguas supuso un "corte" en las condiciones de vida de aquellos hombres de la población: contrariamente a lo que la teoría del contrato social afirma, a saber, que este cambio fue gradual y voluntario, una adaptación orgánica para cambiar condiciones de la vida. Nietzsche ve allí más bien un salto, debido al hecho de que la sociedad es el producto de la voluntad y habilidad de un señor. Esta acción violenta del señor canceló el instinto de libertad en los sujetos, sin ofrecer nada con qué reemplazarlo.

[Nótese que el cambio] no fue ni gradual ni voluntario y que no se presentó como un crecimiento orgánico en el interior de nuevas condiciones, sino como una ruptura, un salto, una coacción, una inevitable fatalidad, contra la cual no hubo lucha y ni siquiera resentimiento. ${ }^{19}$

Aparte de la violencia directa sobre los hombres, esta súbita cancelación de la conducta natural ayudó a hacer de la civilización del hombre un evento penoso.

\subsection{La reacción de los "sujetos"}

iOh demente y triste bestia hombre! iQué ocurrencias tiene, qué cosas antinaturales, qué paroxismo de lo absurdo, qué bestialidad de la idea aparece tan pronto como se le impide, aunque sea un poco, ser bestia de la acción! [...] Aquí hay enfermedad, no hay duda, la más terrible enfermedad que hasta ahora ha devastado al hombre...

GM II 22

Veamos ahora cómo suceden las cosas del lado de los sujetos, dado el hecho de que la constitución de la sociedad es llevada a cabo por un señor. Hasta este punto, he mencionado tres rasgos del proceso de civilización que Nietzsche señala como algo notable por sus efectos psicopatológicos en los sujetos: primero, que la civilización representa el confinamiento e inhibición 
de la manera natural en que se expresa la voluntad de poder; segundo, que esto supuso un corte súbito en el proceso de adaptación del hombre, y tercero, que fue conseguido con violencia, desde el comienzo hasta que la población estuvo completamente formada. La "tensión" causada en el hombre debido a estas condiciones de civilización determinó y, en palabras de Nietzsche, de hecho origina y constituye la cultura. Por consiguiente, las consideraciones siguientes pertenecen a un campo de conocimiento que aquí llamo psicopatología de la civilización. ${ }^{20}$

Según Nietzsche, dichas condiciones de la civilización causan tensión en el hombre de dos maneras principales. Las dos están relacionadas con el papel de los impulsos instintivos en la conducta humana: pues las condiciones de la civilización los hace no sólo inútiles, sino igualmente molestos. De hecho, desde el momento en que la conducta humana se vio forzada a obedecer ciertas reglas, a estimular ciertos actos $\mathrm{y}$, sobre todo, a inhibir otros, el hombre:

a) tuvo que depender de un planear, calcular, coordinar, etc., conscientes; en pocas palabras, tuvo que desarrollar conciencia e inteligencia, las más falibles de sus facultades, en lugar de seguir sus antiguas inclinaciones instintivas, $y$

b) tuvo que buscar opciones alternativas, "subterráneas" de satisfacer las demandas usuales de estos antiguos instintos, sobre todo del instinto de libertad, que nunca dejaron de perseguir sus requerimientos.

Estas dos formas de tensión causaron una disfunción psicológica, tan profundamente arraigada en la cultura que la humanidad todavía padece de ellas. Así, la tarea subordinada que estaba destinada a preparar el último fin de la naturaleza, en cuanto al hombre se refiere, es decir, a volverlo capaz de hacer promesas, se convirtió en un obstáculo para el último paso.

\subsubsection{Primera forma de tensión y ansiedad: la dependencia del pensamiento} consciente. En cuanto a la nueva necesidad de depender de su pensamiento consciente, Nietzsche la considera tan traumante para el hombre como si éste fuera súbitamente obligado a cambiar su habitat. El hombre, dice, fue súbitamente obligado a volverse astuto; pero las innumerables disfuncionès que entonces advirtió en su astucia crearon ansiedad y fueron incluso el origen mismo de la conciencia. ${ }^{21}$ Cuando súbitamente el hombre fue obligado

20 Comúnmente se piensa que este campo de investigación fue descubierto por los psicolo. gos del siglo XX, sobre todo Freud, pero sus lineamientos principales se pueden rastrear, según vemos, hasta Nietzsche, 0 incluso más atrás, hasta Rousseau y su Discurso sobre las ciencias y las artes de 1750.

21 Por cierto que esta idea recuerda mucho la tesis de Heidegger de que la conciencia teórica surge solamente cuando aparecen disfunciones. 
a vivir según leyes sociales, según hechos y consecuencias, fines y medios, etc., que no podía dominar, llegó a ser consciente de sí mismo por primera vez. De ese momento en adelante, supo que compartía una responsabilidad en su futuro. Este cambio de status le hizo la vida interesante, pero también fue un asunto de constante (pre)ocupación y cuidado.

Lo mismo tuvo que ocurrirles a los animales marinos cuando se vieron forzados, o bien a convertirse en animales terrestres, o bien perecer [...] -de un golpe todos sus instintos quedaron desvalorizados y "en suspenso". A partir de ahora debían caminar sobre los pies y "llevarse a cuestas a sí mismos", cuando hasta ese momento habían sido llevados por el agua... ${ }^{22}$

Para entender esta situación, basta con imaginarnos a nosotros mismos puestos de repente en la necesidad de efectuar conscientemente tareas tan naturales como respirar, escoger entre alimento fresco y descompuesto, medir peligros; todo lo que ahora ejecutamos instintivamente. La consecuencia natural sería seguramente la misma ansiedad.

Esta necesidad del hombre de "llevarse a sí mismo a cuestas" y este ser constantemente un problema para sí mismo es el mismo hecho que, según vimos antes, llevó al Adán de Kant "al borde de un abismo", cuando se dio cuenta de su habilidad para guiar su conducta de manera consciente. Según Kant, este "primer hombre" se llenó inmediatamente de terror y ansiedad sobre:

cómo se las iba a arreglar él, que no conocía todavía ninguna cosa según sus propiedades ocultas y sus lejanos efectos. [...] [P] orque, sobre los objetos concretos de su deseo que, hasta entonces, el instinto le había señalado, se le abría ahora una gama infinita de objetos, en cuya elección se encontraba perplejo. ${ }^{23}$

3.2.2. Segunda forma de tensión y ansiedad: la "interiorización de los instintos". En relación con la segunda forma de tensión, a saber, los constreñimientos sociales de las demandas naturales de los instintos, Nietzsche desarrolla una interesante teoría, a la que llama la "interiorización" de las mismas (Verinnerlichung). Así es cómo Nietzsche presenta su teoría:

[E]n lo principal, hubo que buscar apaciguamientos nuevos y, por así decirlo, subterráneos. Todos los instintos que no se desahogan hacia fuera se vuelven hacia dentro [...] [Ú]nicamente con esto se desarrolla en él lo que más

22 GM II 16. Otra vez quiero llamar la atención en la semejanza de estas conjeturas sobre el carácter existencial o, en terminología de Gaos, existenciariamente central de la (pre)ocupación y el cuidado constantes con el tema heideggeriano de la cura. Cuando Nietzsche afirma que el hombre tuvo que "llevarse a cuestas a sí mismo" no dice sino que el ser paso a ser un asunto para el hombre.

23 Kant, op. cit., pp. 72-73. 
tarde se denomina su "alma". Todo el mundo interior [...] fue [...] creciendo [...] en la medida en que el desahogo del hombre hacia fuera fue quedando inhibido. Aquellos terribles bastiones con que la organización estatal se protegía contra los antiguos instintos de la libertad $[. .$.$] hicieron que todos aquellos$ instintos del hombre salvaje, libre, vagabundo, diesen vuelta atrás, se volviesen contra el hombre mismo. ${ }^{24}$

Los rasgos básicos de esta teoría nietzscheana de la interiorización son:

1) que una de las formas en que la voluntad de poder se expresa, y no la menos importante, es la crueldad o agresividad libre;

2) que, aunque el desahogo de esta crueldad es inevitable, los constreñimientos de la organización política evitan que se desahoguen hacia fuera;

3) que, una vez inhibido, el instinto se desahoga, ideal e incluso físicamente, con el agente mismo, y

4) que todas las ideas que el hombre, con la ayuda de la imaginación, construye para reemplazar la usurpada libertad de llevar a cabo sus impulsos instintivos constituyen el "mundo interno de la conciencia", la vida silenciosa del "alma", el "laberinto del pecho".

Esta interiorización es un patrón psicopatológico de conducta, pues es debida a la represión antinatural de la vida, de la libre expresión de la voluntad de poder del hombre, aunque en modo alguno del instinto de libertad en sí. Al torturarse a sí mismo, el hombre consigue ejercer su voluntad de poder y por tanto experimenta placer; aunque la desahoga con el único ser a su alcance, él mismo. Tarde o temprano, este placer en la autotortura lo conduce a la conciencia culpable, la manera ideal y más sofisticada de torturarse a sí mismo.

La hostilidad, la crueldad, el placer en la persecución, en la agresión, en el cambio, en la destrucción - todo esto vuelto contra el poseedor de tales instintos: ése es el origen de la "mala conciencia". ${ }^{25}$

Esta teoría de la interiorización presagia la teoría freudiana de la esquizofrenia; aunque ella misma depende de, a su vez, y mejora la concepción rousseauniana de la personalidad dividida bajo la civilización, tal como se encuentra en el Discurso de 1750 . La cercanía del concepto de la mala conciencia a los conceptos freudianos del superego y la esquizofrenia es más clara si observamos que Nietzsche la llama también "la vivisección de la conciencia" (véase GM II 24). La semejanza con Freud no es ningún descubrimiento; aunque el antecedente rousseauniano tal vez sea más novedoso.

24 GM II 16.

25 GM II 16. 
4. La cultura de la mala conciencia

No es en ellos [los "señores" y organizadores natos] en donde ha nacido la "mala conciencia", esto ya se entiende de antemano - pero esa fea planta no habría nacido sin ellos, estaría ausente si no hubiera ocurrido que, bajo la presión de sus martillazos, de su violencia de artistas, un ingente quantum de libertad fue arrojado del mundo, 0 al menos quedó fuera de la vista, y, por así decirlo, se volvió latente. Ese instinto de la libertad [o voluntad de poder], vuelto latente a la fuerza [... ] ese instinto de la libertad reprimido, retirado, encarcelado en lo interior y que acaba por descargarse y desahogarse tan sólo contra sí mismo: eso, sólo eso es, en su inicio, la mala conciencia.

GM II 17

El hombre [civilizado] que, falto de enemigos y resistencias exteriores, encajonado en una opresora estrechez y regularidad de las costumbres, se desgarraba, se perseguía, se mordía, se roía, se sobresaltaba, se maltrataba impacientemente a sí mismo, este animal al que se quiere "domesticar" y que se golpea furioso contra los barrotes de su jaula, este ser al que le falta algo, devorado por la nostalgia del desierto, que tuvo que crearse a partir de sí mismo una aventura, una cámara de suplicios, una selva insegura y peligrosa - este loco, este prisionero añorante y desesperado fue el inventor de la "mala conciencia".

GM II 16

Señalé ya la conjetura nietzscheana acerca de las consecuencias psicológicas principales de la civilización, es decir, que la inhibición de los instintos del hombre encarcelado resultó en la reversión patológica de la agresividad contra el hombre mismo. Este hombre civilizado y autotorturado, dice Nietzsche, es el que "inventó" la conciencia culpable, y precisamente como un medio excelente de autotormento. Quisiera aclarar ahora cómo se supone que dicho medio ha de lastimar y cómo se supone que el hombre llegó a idearlo, en pocas palabras, qué es exactamente la conciencia culpable.

He llegado al punto en que la explicación nietzscheana de la conciencia culpable desgraciadamente carece de explicitud. Aunque Nietzsche es bastante claro en cuanto al origen de la conciencia culpable, resulta más bien indirecto y corto de palabras en lo que se refiere a su estructura y su funcionamiento. He aquí mi interpretación de ambas cosas. Si estoy en lo correcto, el hombre con autotortura interiorizada inventa la conciencia culpable al aprovechar el hecho, debido a la herencia cultural y a la moralización de la estructura de la vieja relación entre deudor y acreedor, de que, en su mente, culpa (o deuda) y sufrimiento se han llegado a conectar intimamente. Ésta es mi principal hipótesis interpretativa. Paso ahora a revisar en qué 
medida consigue dar consistencia orgánica a todas las tesis de Nietzsche que mencioné arriba.

\subsection{La conexión de la culpa con el sufrimiento}

En esta esfera, es decir, en el derecho de las obligaciones es donde tiene su hogar nativo el mundo de los conceptos morales "culpa" [Schuld], "conciencia", "deber", "santidad del deber" [... ] Ha sido también aquí donde por vez primera se forjó aquel siniestro y tal vez ya indisociable engranaje de las ideas "culpa y sufrimiento".

GM II 6

En una tesis que Nietzsche considera una de su más innovadoras, declara que "el capital concepto moral 'culpa' [Schuld] procede del muy material concepto 'tener deudas' [Schulden]" ${ }^{26}$ Este origen material de los conceptos de "culpa" y "castigo" son las relaciones contractuales comunes y su concepto correspondiente de justicia, según el cual la cantidad de dolor y sufrimiento en el castigo debe ser comparable e incluso proporcional a la deuda. Es debido a su origen en esta relación casi aritmética que, cuando la deuda se "moralizo", también tuvo que hacerlo el castigo. Pero Nietzsche quiere ir más atrás y averiguar cómo es que los conceptos mismos de "deuda" y "sufrimiento" pudieron llegar a tener semejante conexión. Le parece sorprendente y digno de indagación que se haya llegado a aceptar que una deuda material sea pagada, no sólo materialmente y, digamos, en efectivo; como parece lógico, sino también con un derecho de hacer sufrir. En pocas palabras, se pregunta qué condiciones explican el surgimiento del concepto de "castigo".

Escribí antes que el dolor es el único medio para crear memoria en el hombre natural. Sólo el uso intensivo del castigo resultó en ese dominio del hombre sobre sus afectos que normalmente llamamos "su razón". Originalmente, decimos ahora, el castigo estaba asociado con contratos privados, en los que un deudor empeñaba su propia integridad física, su libertad o hasta su vida, para crear confianza en el acreedor y para forzarse a sí mismo a recordar su promesa. Los primeros objetos con los que la incipiente "razón" estaba asociada eran promesas relacionadas con contratos comerciales, deudas. Aquí aparece la importancia de lo que dijimos antes sobre la voluntad de poder activa en todos los individuos de la sociedad, sean señores o súbditos, y sobre su eventual expresión mediante la crueldad. Que el sufrimiento del deudor pudiera ser aceptado como un reemplazo válido de un daño material causado, se basa en el hecho de que hacer sufrir a los otros causa placer y esto, a su vez, sólo puede ser explicado por una 
crueldad instintiva que, en ciertas circunstancias, va unida a la voluntad de poder. Ningún fundamento adicional puede explicar este hecho:

Ver sufrir produce bienestar; hacer sufrir, más bienestar todavía —ésta es una tesis dura, pero es un axioma antiguo, poderoso, humano - demasiado humano... ${ }^{27}$

Mas, para formar una sociedad estable, el Estado emergente tuvo que privar a los hombres de la posibilidad de infligir ellos mismos el castigo. Los primeros códigos penales tienen el sentido de moderar la antigua "ley" de la vendetta. En tanto agente introductor de la civilización entre los sujetos, la meta principal del Estado era forzarlos, en cada caso, a alcanzar un arreglo. El primer canon de justicia que, para ello, introdujo el Estado establece que "cada cosa tiene su precio; que todo puede ser pagado". ${ }^{28}$ De acuerdo con este canon, todo perjuicio tiene un equivalente y se puede restaurar, por lo menos con un dolor del deudor proporcional al daño. Ésta es la meta de los primeros códigos penales, es decir, un esfuerzo del Estado para contener la ira recíproca de sus sujetos y sus efectos destructivos. Su característica común es que consagran la asociación de deuda y sufrimiento, e incluso establecen una razón entre daños materiales y la satisfacción afectiva de hacer sufrir.

[T]odo [determinado] perjuicio tiene en alguna parte su equivalente y puede puede ser realnente compensado, aunque sea con un dolor [determinado] del causante del perjuicio. ${ }^{29}$

De esta manera, el castigo representa un eminente instrumento de la civilización y está asociado al origen del pensamiento objetivo mismo, pues acompaña la introducción dé la justicia.

Fijar precios, tasar valores, imaginar equivalentes, cambiar -esto preocupó de tal manera al más antiguo pensamiento del hombre, que constituye, en cierto sentido, el pensar $[\ldots]^{30}$

El verdadero poder de un Estado podría ser medido por su capacidad para contener tales desahogos de enojo y venganza, de definir equivalencias entre daño y castigo, de monopolizar la ejecución de castigos e incluso proteger al malhechor de la ira desenfrenada del perjudicado. Las códigos penales fueron introducidas por el señor para modular los efectos destructivos de los sujetos. Representan la racionalización, i.e., la introducción de

27 GM II 6.

28 GM II 8.

29 GM II 4.

${ }^{30}$ GM II 8. 
mensurabilidad y límites en el ámbito de los afectos que amenazaban la estabilidad del todo social.

Ésa es la explicación nietzscheana de la asociación de deuda y sufrimiento. Todavía le falta explicar cómo la culpa se adecua a la meta de la autotortura. Esta explicación se basa en su teoria sobre la "moralización" del concepto de deuda, que ahora vamos a ver.

\subsection{La "moralización" de la relación entre deudor y acreedor: la conciencia culpable}

Hemos visto lo que la conciencia culpable es en sus orígenes, es decir, la voluntad de poder del hombre civilizado, reprimida y finalmente habilitada para desahogarse sólo en sí misma. Ciertamente esto es en sí mismo una enfermedad seria, que puede manifestarse - como hoy en día está bien probado- ${ }^{31}$ en las más diversas conductas destructivas individuales y sociales, tales como disfunciones psíquicas y psicosomáticas. $Y$ a pesar de eso, añade Nietzsche, esta enfermedad todavía se ha "espiritualizado" y convertido en la fuente constructiva de muchas o quizás todas las formas culturales, i.e., de ideales. Para él, la autocrueldad es, en efecto, el sustrato de toda nuestra cultura, aunque algunos de su modos ideales puedan engañarnos. Apenas se nos hubiera ocurrido pensar, por ejemplo, que un género de belleza, y quizás la belleza misma, haya tenido origen en el autotormento, y así muchas otras manifestaciones cuyo valor recae en lo "altruista". La generación de la belleza es, sin embargo, tópico para otra reflexión. Ahora quisiera seguir el desarrollo posterior de la conciencia culpable, desde este original y amplio concepto de la autocrueldad hasta la forma propia y madura de la conciencia culpable. Esto ocurrió con la "deificación" de la autotortura, cuando el hombre cristiano acuñó su ideal de "Dios".

La conciencia culpable, en su sentido propio, es el medio que el hombre cristiano civilizado inventó para atormentarse a sí mismo psíquicamente por medio de un ideal. Desarrolló este complicado recurso, según Nietzsche, "moralizando" la estructura culturalmente heredada de la relación crédito/deuda, previamente cristalizada en la forma de presupuestos religiosos; en otras palabras, incorporando los conceptos ancestrales de culpa y deber a la voluntad de autotormento. En esta forma los conceptos de una "impagable deuda o culpa original" y los "deberes hacia los dioses" se volvieron siempre más ubicuos, más espirituales, hasta que llevaron la autotortura hasta su más horrendo extremo.

Nietzsche relata el proceso en la siguiente manera. El hombre prehistórico, dice, inventó a los dioses por miedo no de la naturaleza, sino de sus

31 Véanse, por ejemplo, las obras de Henri Laborit o, para una introducción sumamente entretenida a sus teorías y experimentos, la película Mon oncle d'Amerique dirigida por Alain Resnais, Francia, 1980. 
señores ancestrales, pues era forzado a reconocer una deuda con el Estado y por lo tanto con su fundadores. Naturalmente que, cuanto más poder alcanzaba un Estado y más ventajas obtenían su ciudadanos, más alta les parecía la deuda. Esto dio lugar a la necesidad de pagos periódicos. Ahora bien, para entonces el dolor y el sufrimiento, como sabemos, ya contaban como pagos de deudas y eran tan apreciados como cualquier retribución en efectivo, o incluso más. Así, los sacrificios llegaron a ser un deber para la clase gobernante y extensivamente para los súbditos. Naturalmente que los sujetos encerrados en el Estado acceden al sacrificio y hasta gozan con él, pues su espectáculo da salida a su voluntad de autotortura.

Hasta ese punto, los conceptos de deuda y deber con el Estado se habían espiritualizado en la forma de religión; aunque todavía no se moralizaban del todo. Lo previsible, en semejante situación, es que un progreso del ateísmo en la Tierra, como el que trajo la edad moderna, hubiera promovido una segunda inocencia, hubiera liberado a la humanidad de la mala conciencia, " "de todo sentimiento de endeudamiento culpable hacia su origen, su causa prima". ${ }^{32}$ Pero aquí los hombres de la mala conciencia efectuaron una maniobra con la que desligaron la culpa ancestral de los presupuestos religiosos y así lograron llevar a cabo su moralización, preservándola para su autotormento. Al "moralizar" los conceptos de "deuda" y de "deber", estos hombres apuntaron a invertir su progreso hacia una segunda inocencia, a cerrar la posibilidad de cualquier exculpación final. Pues tal moralización no sólo hizo la culpa del deudor indeleble, incluso esencialmente inherente, sino que también la virtió en el acreedor, sea éste el primer hombre o la naturaleza y su legado, o sea, la existencia en general, considerándolos malignos y sin valor. Una vez que la culpa, el deber y el sacrificio, se moralizaron, i.e., se espiritualizaron totalmente, la mala conciencia aseguró su camino hacia el grado más alto, independientemente de que la fe en el Dios acreedor declinara o no.

[El] hombre de mala conciencia se ha apoderado del presupuesto religioso [i.e., la deuda con sus ancestros] para llevar su propio automartirio hasta su más horrible dureza y acritud. Una deuda con Dios; este pensamiento se le convierte en instrumento de tortura. [...] Es ésta una especie de demencia de la voluntad en la crueldad anímica que, sencillanente, no tiene igual: la voluntad del hombre de encontrarse culpable y reprobable a sí mismo hasta resultar imposible la expiación, su voluntad de imaginarse castigado sin que la pena pueda ser jamás equivalente a la culpa, su voluntad de infectar y de envenenar con el problema de la pena y la culpa el fondo más profundo de las cosas, a fin de cortarse, de una vez por todas, la salida de ese laberinto de "ideas fijas", su voluntad de establecer un ideal —el del "Dios santo"-, para adquirir, en presencia del mismo, una tangible certeza de su absoluta indignidad. ${ }^{33}$ 
Así es como esa voluntad del hombre de mala conciencia, por hallarse culpable y merecedor de castigo, "alcanzó su altura más terrible y más sublime". Resumo esta moralización progresiva de la culpa. El hombre de la mala conciencia mistifico, primero, al Estado, ubicando la deuda impuesta al Estado en acreedores ancestrales, tales como "padres fundadores", etc. Después deificó a los acreedores ancestrales, privándolos a ellos, y por consiguiente a la deuda misma, de toda mensurabilidad o racionalidad. Y para culminar, la tradición cristiana santificó al acreedor divino, haciendo que Dios pagara la deuda él mismo por nosotros. Con este último paso moralizó la deuda y nos hizo irredimiblemente culpables e indignos.

Según Nietzsche, la forma última de la mala conciencia, una voz interna que condena toda manifestación de nuestros instintos y nuestra voluntad, representa el fin de este largo proceso de moralización del concepto de "deuda". Una vez que se consigue, el retorno a la inocencia ha sido bloqueado. Ya llevamos al acreedor dentro de nosotros mismos. Dios ha muerto, pero sólo para la causa de un acreedor mucho más perenne y omnipresente dentro del hombre.

La completa moralización de la culpa significa, además, una división de la personalidad del hombre civilizado, quien viene a ser el deudor y el ejecutor simultáneamente. El lenguaje mismo que la mala conciencia usa, y quizás inventó, i.e., el modo subjuntivo: "hubiera hecho", "podría haber hecho", "debería haber hecho", este lenguaje guarda huella de su bajo sentido de la realidad, característico del desdoblamiento de personalidar! que conocemos como "esquizofrenia". Lo que normalmente se considera $s$ r la condición de la mala conciencia, o sea, la libertad moral, es más bít 1 un producto, una invención del hombre de mala conciencia. De hecho, la :nala conciencia, la voz interna que tan consistentemente le recuerda al hombre su culpabilidad, no surge en él a causa de que conozca que "podía haber hecho diferente", que "debía hacer diferente, pero hizo, inmoralmente y sin embargo, lo que le dio la gana". Por el contrario, todo este conocimiento, toda esta "conciencia" es inventada por el hombre esquizofrénico para justificar y acrecentar su autotortura, como una forma de "crearse a base de sí mismo'una aventura, una cámara de suplicios, una selva insegura y peligrosa".34

\section{Conclusiones}

Después de estas consideraciones creo haber mostrado que lo que a primera vista parece un puñado de conjeturas inconexas sobre las condiciones originales de la civilización o sobre sus consecuencias para la cultura forma, en realidad, una teoría estructurada de psicopatología de la civilización, 
incluso, un sistema apto para interpretar la política y valorar las formas artísticas. El concepto fundamental de este sistema es "voluntad de poder" o "instinto de libertad". No sólo he afirmado que lo sea, sino que he mostrado, creo, cómo es que esta fuerza explica los diversos modos de conducta en diferentes individuos y situaciones, así como las fases históricas que Nietzsche distingue. Además, he señalado ocasionalmente que esta teoría representa un paso importante en el avance desde las conjeturas semimitológicas sobre los orígenes de la civilización y la especificidad del ser humano, hasta la investigación científica acerca de los efectos de la civilización sobre la personalidad y la cultura, en el cual he apuntado a Rousseau, Kant y Heidegger como puntos nodales. Algunas de las tesis nietzscheanas más relevantes e innovadoras son: (1) que, para que surga el Estado, es necesaria una centralización del poder o un agente externo con poder para el Estado; (2) que al ser inhibida la agresividad del hombre civilizado, poniéndolo en tensión y ansiedad, ésta experimenta una autodestructiva reversión; (3) que esta agresividad contenida se expresa subliminalmente en la construcción de figuras culturales; (4) que es preciso admitir en el hombre una fuerza activa de olvidar como parte de sus instrumentos de supervivencia, y que esta fuerza se explica suficientemente por la naturaleza de la voluntad de poder, y (5) que los presupuestos religiosos tienden a moralizarse. Muchas de estas tesis han sido probadas ahora e incluso han llegado a ser principios metodológicos en distintas ciencias de la vida, como la sociología, la psicología, la biología y la historia.

De cualquier modo, el logro más importante de esta teoría es que todas estas tesis pueden derivarse sistemáticamente del concepto fundamental de "la voluntad de poder" y de sus leyes fundamentales. Esta derivación, cuya forma he tratado de delinear más o menos, no la llevó a cabo Nietzsche, y quedó como tarea para las ciencias humanas. Pero, al vislumbrar tantas leyes naturales desde el punto de vista de este concepto, sí demostró que este concepto puede resultar tan rico en consecuencias para esas ciencias como los conceptos newtonianos de "inercia" resultaron para la mecánica.

Como una última prueba de que mi interpretación de GM II es correcta, quisiera mostrar el papel que esta teoría desempeña en la comprensión que Nietzsche tiene de Wagner, y cómo mi interpretación de la misma explíca tanto la exaltación del Wagner de El anillo del nibelungo como la violenta reacción contra el Wagner del Parsifal. El siguiente apéndice tiene, pues, el propósito de delinear una interpretación de El anillo acorde con las teorías nietzscheanas ya explicadas y de señalar el sentido en el que el Parsifal tenía que parecer, a los ojos de Nietzsche, una renuncia de Wagner al ideario que habían compartido. 
Apéndice sobre la Genealogía de la moral y Wagner

En la $G M$, Nietzsche parece aludir y criticar la conversión de Wagner a la filosofía del pesimismo de Schopenhauer y su cruzada por los valores cristianos. Si mi percepción es correcta, el segundo ensayo de la $G M$ no es más que una sistematización filosófica de El anillo, dedicada a estimar su valor y, al mismo tiempo, a mostrar su falta de consistencia con los valores de autonegación expresados en Parsifal. Trazando rasgos muy amplios, creo que, en contraste con Parsifal y la moral del Wagner tardío, la GM reivindica los valores de $E l$ anillo, la versión sigfridiana del redentor y las primeras ideas preschopenhauerianas de Wagner.

Al igual que el segundo ensayo de la $G M, E l$ anillo del nibelungo es la historia del comienzo, la paradoja y el fin último de la civilización. El Rin dorado es la imagen del seno de la naturaleza en el que el hombre-animal vive despreocupadamente. En el acto de aborrecer el amor a cambio del oro y el anillo del poder, Alberich, un nibelungo, representa el momento en que el hombre empieza a tener diferencias con sus instintos y pierde la inocencia original. La maldición que desde entonces acompaña al anillo, representa una enfermedad que el género humano entero desarrolla, pronto y en todas sus clases, y que Nietzsche interpreta como la conciencia culpable. El meollo de la trama está, como en la explicación nietzscheana, en un dilema que parece imposibilitar la continuación del progreso humano hasta su último estadio. Este dilema no es otro que la paradoja que Votán descubre en el primer acto de La valquiria. Lo paradójico de su situación consiste en que necesita restituir al hombre su libertad original precisamente por medio de la civilización. Parecería que la única manera que el hombre civilizado tiene para recobrar su buena conciencia original fuera alejándose aún más de la naturaleza. La civilización es más que el único medio que Votán domina. Es su esencia misma. Por eso, reniega de su naturaleza, de "esos lazos que me atan", cuando no ve salida al dilema.

Me convertí en gobernante a través de tratados; a causa de mis tratados estoy ahora esclavizado. ${ }^{35}$

Esta paradoja no es distinta de la que habíamos señalado en la $G M$, a saber, que formar un individuo autónomo, soberano y de buena conciencia a partir de un animal naturalmente veleidoso supone, como tarea preparatoria, engendrar antes a un hombre moral, civilizado y de mala conciencia; pero como “'moral' y 'autónomo' se excluyen mutuamente", el hombre moral no puede pasar a la fase final de la cultura, pues no tiene ya la fuerza para liberarse de su mala conciencia; y así, mientras más progresa la humanidad en su civilización, más parece alejarse de su meta. En El anillo hallamos 
la primera progresión, la que va hasta el hombre moral, en la prolongada producción de hombres, cada vez más responsables, de "héroes", que las valquirias van acumulando. Su producto más acabado es el último héroe que la civilización (Votán) y la eticidad de las costumbres (Frica) pueden producir, lo que Nietzsche llamaría "el último hombre": Segismundo. Pero el mayor problema de Votán radica en el paso de este último hombre al hombre de la segunda inocencia, pues lo obstruyen precisamente los compromisos de la sociedad y la eticidad, cuya fuerza es representada en los reclamos de Frica. En este punto nos damos cuenta de que lo que la civilización realmente debe traer es la liberación de la voluntad (el anillo) de esa enfermedad que es la mala conciencia (la maldición de Alberich) que resulta obstaculizada por la misma civilidad (los códigos de los contratos privados, escritos en la lanza de Votán) y la eticidad de las costumbres (las sagradas costumbres de Frica) que alguna vez dieron a la humanidad dominio sobre sus impulsos salvajes y "expulsaron de la Tierra" la posibilidad de que los impulsos animales se desahogaran destructivamente. $Y$ por eso el empeño de Brunilda por recuperar el anillo, desafiando las condiciones de Frica, representa la verdadera, pero secreta e inconfesable, voluntad de Votán. Sólo ahora se da cuenta la civilización de la contradicción entre sus fines finales y los inmediatos, de que su personalidad se ha desdoblado (hecho que se representa por el desacuerdo entre Votán y Brunilda) y de que sus propios códigos la tienen atada. Votán confiesa, entonces, ser "el menos libre [...] [y] el más triste de todos los seres". ${ }^{36}$

Pero la paradoja no termina aquí, pues Votán también se da cuenta de que ningún hombre de la cultura del momento, sino sólo un hombre hecho a sí mismo, un ateo e iconoclasta, un hombre ingenuo, incivilizado y con buena conciencia, podría liberar la voluntad humana de su presente encierro y alcanzar la segunda inocencia. La paradoja de Votán consiste en la imposibilidad de obtener al redentor de la humanidad desde la cultura de ideales negativos que él mismo representa. En El anillo, la redención de la humanidad, la nueva humanidad sin relación alguna con la civilización previa, está representada mediante Sigfrido. En efecto, Sigfrido se crió entre animales, confiando, como ellos, en sus instintos. El arma que utiliza la forjó él personalmente, a partir de los pedazos de la de Segismundo, quien, a diferencia de aquél, la recibió de mano de Votán. Sigfrido, en cambio, ignora todo acerca de Votán y de las restricciones de la civilización. Incluso tiene un enfrentamiento con-Votán cuando éste, al pie de la montaña de Brunilda, quiere impedir su acceso. Sin pensarlo dos veces, Sigfrido lo hace a un lado, rompe la lanza de los códigos, y alcanza y libera a Brunilda, quien, como dije antes, representa la verdadera voluntad de Votán, oculta por el amenazante cerco de prejuicios que Votán mismo había hecho levantar. 
La imposibilidad de resolver el problema sin un redentor inocente y ajeno a él se hace evidente en el discurso de Votán a Brunilda, en el segundo acto de La valquiria, cuando Votán se da cuenta del profundo sentido y la inescapabilidad de su dilema:

Les ordené a ustedes [valquirias] que me trajeran héroes, tal como alguna vez decretamos magistralmente en nuestras leyes; hombres cuyo espíritu nosotros [los dioses] sujetáramos, y a los que, a través de tratados confusa y engañosamente limitantes, los retuviéranos con ciega obediencia a nosotros... ${ }^{37}$

Pero esos héroes, continúa Votán, aunque hayan sido suficientemente fuertes contra "las fuerzas de la oscuridad", no pueden hacer nada contra quienquiera que posea el anillo, pues ése domina la voluntad de todo hombre "civilizado". Por eso, Votán no puede ni arrebatar él mismo el anillo a Fafner, ni hacer que lo hagan los héroes civilizados; sino que sólo puede confiar en que aparezca un héroe ingenuo y ajeno a toda civilización, único invulnerable al influjo del anillo y, por tanto, a la maldición del nibelungo.

Sólo una persona podría hacer lo que yo no puedo: un héroe al que yo nunca me haya inclinado a ayudar. Un extraño para el dios, libre de sus favores, ingenuo y espontáneo, por sus propias necesidades con sus propias armas, podría hacer la hazaña que yo debo evitar, y que nunca he sugerido, aunque ello sea mi único anhelo. Este hombre opuesto a los dioses quien luchará por mí, este enemigo amistoso, ¿cómo puedo hallarlo? ¿Cómo puedo crear un agente libre a quien nunca haya protegido, quien por desafiarme será tanto más querido para mí? ¿Cómo puedo hacer a ese otro, quien no sea ya parte de mí, quien de su propio acuerdo haga lo que yo sólo deseo? iQué predicamento para un dios, una desgracia dolorosa! Con qué aversión me encuentro sólo a mí mismo siempre, en todo lo que creo. El otro hombre por quien yo suspiro, ese otro que nunca puedo encontrar, pues el hombre libre tiene que crearse a sí mismo; y yo sólo puedo crear sujetos a mí mismo. ${ }^{38}$

Me parece innegable la semejanza de esta aporía y de este cuadro del redentor con los que traza Nietzsche al final del segundo ensayo de la GM.

Nosotros los hombres modernos - dice ahí- somos los herederos de la vivisección durante milenios de la conciencia, y de la autotortura, también durante milenios, de ese animal que nosotros somos. [...] Durante demasiado tiempo el hombre ha contemplado "con malos ojos" sus inclinaciones naturales, de modo que éstas han acabado por hermanarse en él con la "mala conciencia". Sería posible en sí un intento en sentido contrario - ipero quién es lo bastante fuerte para ello? [...] ¿A quién dirigirse hoy con tales esperanzas y pretensiones?... iTendríamos contra nosotros justo a los hombres buenos! 
[...] Para lograr aquel fin se necesitaría una especie de espíritus distintos de los que son probables cabalmente en esta época [...] Ese hombre del futuro, que nos liberará del ideal existente hasta ahora y asimismo de lo que tuvo que nacer de él, de la gran náusea, de la voluntad de la nada, del nihilismo, ese toque de campana del mediodía y de la gran decisión, que de nuevo libera la voluntad, que devuelve a la tierra su meta y al hombre su esperanza, ese anticristo y antinihilista, ese vencedor de Dios y de la nada -alguna vez tiene que llegar... ${ }^{39}$

Pero Wagner no proveyó uno, sino dos modelos diferentes del redentor, en dos momentos distintos de su vida. Además de Sigfrido, el iconoclasta, más tarde propuso a Parsifal, el héroe santo de la autonegación. El primero pertenece al Wagner de los años entre la Revolución de 1848 y 1877; el segundo pertenece al último Wagner. Aparentemente él cambió su concepción del redentor después de leer a Schopenhauer. En mi opinión, Nietzsche interpreta este cambio como algo equivalente a la moralización de la culpa religiosa, aquel "entrelazamiento de la mala conciencia con el concepto de Dios", 40 del que ya hemos hablado, "destinado a obstruir definitivamente la salida de ese laberinto de 'ideas fijas' que es la mala conciencia". ${ }^{41} \mathrm{Y}$ en efecto, a diferencia de Sigfrido, quien debe redimir a la voluntad de poder del hombre y a los instintos naturales, Parsifal está destinado por Wagner a liberar al hombre de la voluntad de poder y del esfuerzo por el placer mismo. En este respecto, Parsifal tenía que parecerle a Nietzsche el ideal asceta que tanto rechaza, y el cambio de Wagner, como una claudicación del viejo revolucionario anarquista de 1848 . 